\title{
Ngā Aroro and Social Work Supervision
}

\author{
Eliza Wallace, Ngāpuhi, Te Rarawa, Violence prevention sector
}

\begin{abstract}
INTRODUCTION: This article explores the interconnectivity between Te Ao Māori (Māori worldview) concepts and supervision.
\end{abstract}

METHOD: The main focus of the research was to highlight ngā aroro (key concepts) from Te Ao Māori that influence critical reflection in supervision and the cultural effectiveness of supervision. The embedding of kaupapa Māori (Māori approaches) research principles and ethics meant that the methodology provided a supportive shelter for consciousness-raising, critical dialogue, reflection on supervision practice and for oral cultural narrative to be honoured. A unique part of the methodology was the inclusion of a Whakawhanaungatanga Research Advisory Roopu, which provided the necessary cultural oversight of the research.

FINDINGS: The research used a thematic analysis that brought to light six conceptual themes from Te Ao Māori to unlock heightened holistic learning and support in supervision practice. The findings revealed that customary knowledge, skills and methods were purposefully accessed to enable the re-indigenising of social work supervision. The conceptual frameworks showed elements of co-design, an awakened spiritual awareness and a desire to explore one's cultural sense of self.

IMPLICATIONS: The research challenges the conventions of social work supervision to review supervision theory and practice particularly in considering the strengths of supervision provided by non-registered social work supervisors and the cultural effectiveness of supervision being developed, measured and evaluated based on the supervision goals of the supervisee and indigenous aspirations.

KEYWORDS: Ngā aroro; Māori concepts; supervision; culturally effective; indigenous
AOTEAROA NEW ZEALAND SOCIAL WORK 31(3), 20-31.

CORRESPONDENCE TO: Eliza Wallace

elizawallace@xtra.co.nz

\section{He timatanga-introduction}

At times in supervision I have felt an uneasy tension at the precipice of where it is said that supervision and culture collide (Rewita, Swann, Swann, \& Crocket, 2017). This is partially because at times I could not hear, see and feel my culture surrounding me in my supervision, in addition to my desire and need to know who I am as wāhine Māori (Māori woman) and to practise with cultural integrity (Wallace, 2018). The supervision reality for me often felt more like a tenuous balancing act of meeting the professional administrative tasks of supervision (Davys \&
Beddoe, 2010; Davys, May, Burns, \& O'Connell, 2017) alongside trying to achieve authentic cultural congruency, which I needed to be unprescribed from a western lens or professional competency frame (Swann et al., 2017). Consequently, as a supervisor and supervisee, my supervision sessions became more about trying to enable reflective shifts based upon intergenerational ancestral knowledge and practice (Thomas \& Davis, 2005).

Swann (2017) described this cultural reality in supervision as the disruption of the predetermined professional narrative 
in supervision with the privileging of customary knowledge and practices from Te Ao Māori. Consequently, this research explored the presence of Māori concepts as determinants that enable heightened critical reflection, learning opportunities and cultural effectiveness in supervision for social workers.

\section{Ngā aroro-concepts from Te Ao Māori}

According to Mead (2003), ngā aroro are linked to historical and contemporary contextual influences that inform a Māori worldview, particularly resonating in Te Ao Māori belief and value systems. Mead (2003) and Marsden and Royal (2003) highlighted the difficulties of identifying ngā aroro through the impacts of colonisation and the loss or suppression of customary knowledge, and stressed that, equally important is recognising the depth of understanding required in the meanings of each concept. By the same token, Pere (1982) pointed out that ngā aroro need to be truly understood in their totality, as each concept is intrinsically associated to the others, and are key to relational, applied knowledge and practice.

Barlow (1991) examined and described over 70 ngā aroro in everyday use, for example, wairua (non-physical, spirituality) and manaaki (care of others). In addition, authors Mead (2003) and Tate (2012) highlighted the intricate interplay of ngā aroro by saying that they can also be considered values. Furthermore, Marsden and Royal (2003), Eruera (2005) and Mead (2003) added that values and principles are related to ngā aroro in terms of guiding the use of ngā aroro in their correct practice and / or in the standards of behaviour required, for example, during the powwhiri (the process of a formal welcome ceremony). For these reasons, Pere (1982) suggested that ngà aroro, along with associated principles and values, are grafted from a shared source code, adding that they need to be understood in their whole living-being.

\section{Social work supervision}

There is general agreement about the functions of supervision being: educational, supportive and administrative (Kadushin, 1976) and, respectively, as developmental, resourcing and qualitative (Hawkins \& Smith, 2006, as cited in Hawkins \& Shohet, 2012). Moreover, Davys and Beddoe (2010) noted an additional function, mediation described by Morrison (2001). For Morrison (2001, p. 29) the mediation function is the negotiation of the different, and sometimes competing, aspects of the supervision encounter with various stakeholders in consideration.

Many approaches to supervision emphasise the learning dimensions. Shohet (2011) deferred to Carroll's description of supervision as a journey of learning. Furthermore, Tsui (2004) and Wonnacott (2011) suggested that transformational learning in supervision occurs through the establishment of a trusting supervisory relationship upon which the successful transmission of social work knowledge is based. Hawkins and Smith (2006, as cited in Hawkins \& Shohet, 2012) argued that for learning in supervision to be transformational and similarly translated as such in the practice setting, the supervisee not only experiences a different way of thinking but also a different way of feeling about a situation.

The central importance of culture in supervision has been discussed in international and Aotearoa New Zealand literature. Tsui and Ho (1997) identified supervision as being embedded in the context of culture, while Elkington (2014) described how raised consciousness about the need for cultural supervision has been triggered more recently by cultural safety concerns in the health sector (Wepa, 2015). This is not to minimise the foresight and effect of early proponents of cultural supervision models such as WebberDreadon's (1999) Awhiowhio model. Early kaupapa Māori indigenous approaches like 
the Awhiowhio model sought cultural equity in supervision for Māori social workers, and were in tune with the indigenous rights movements occurring in the 1990s in response to the breaches of Te Tiriti o Waitangi (1840).

Cultural supervision appears to have flourished over the past two decades in Aotearoa New Zealand with evidence of a number of cultural supervision models in the local literature (Su'a-Hawkins \& Mafile'o, 2004; Tsui, 2004; Connolly, Crichton-Hill, $\&$ Ward, 2005). However, Elkington (2014), Scerra, (2012) and Eruera (2005) share the view that professional supervision is heavily influenced by a predominately western perspective and encourage more indigenous supervision research to be undertaken.

There is evidence of the influence of western perspectives in cultural supervision and none more so than with the proposition that cultural supervision is framed around social work competency (Elkington, 2014), rather than competencies more akin to cultural accountability, for example, to whānau (family group), hapū (sub-tribe) and iwi (tribal affiliation) measures. In addition, Eruera (2007) highlights the lack of indigenous specificity that the broadness of the use of a term such as cultural supervision signals, for example, the status of Tangata Whenua (the indigenous people of the land) in Aotearoa lacks clarity. Concern has similarly been raised around cultural supervision being viewed as an optional extra or not being considered as rigorous as professional social work supervision (Scerra, 2012).

The local acuity for authentic indigenous supervision models such as kaupapa Māori supervision is well founded and documented in local literature (Eketone, 2012; Elkington, 2014; Eruera, 2005; Murray, 2012; Pohatu, 2004; Webber-Dreadon, 1999). Kaupapa Māori supervision has drawn attention globally, being viewed as leading cuttingedge indigenous social work supervision models of practice (Scerra, 2012). This is clear even in early indigenous supervision models and illustrated in Webber-Dreadon's (1999) indigenous supervision model, which points to the significance of expertise sitting outside the supervision alliance through the inclusion of kaumātua and kuia or the cultural knowledge of tribal elders in supervision. Further advances include the important practice of applying ancestral knowledge of takepū or principles in supervision (Pohatu, 2004).

The necessity of providing opportunities to critically reflect on appropriate ways of working alongside and, therefore, in harmony with Māori in order to build social worker confidence and to give an assurance of safe practice was described by Eketone (2012). In outlining a framework of culturally effective supervision which is beneficial to the supervision needs of Māori social workers, Eketone reviewed the culturally effective social work supervision functions. Included is the wairua function (Durie, 1994) or the spirituality dimension for Māori, which Eketone (2012) suggested encompasses aspects of the social practice experience which may be outside of a social worker's standard knowledge base. According to Eketone (2012), a key difference in culturally effective social work supervision is in the function of this type of supervision which has more of an emphasis on the spiritual and cultural protection of the supervisee, the supervisee's agency and the client.

\section{Method}

\section{Kaupapa Māori research methodology}

For this research, a dual approach, combining the use of the key principles of kaupapa Māori methodology (Mooney, 2012; Moyle, 2014; Smith, 2012) with a qualitative interview method (Patton, 2015), was utilised. The intention of this research was not to examine all facets of cultural social work supervision practice in detail, rather it was to highlight ngā aroro that enhance culturally effective social work supervision practice in contemporary Aotearoa. 
The incorporation of kaupapa Māori research principles, for example, "kanohi kitea (the seen face)" (Moyle, 2014, p. 32)—to present yourself to people face-to-face-allows the researcher to explore culturally rich data uninhibited by the emotional intent, body language and subtleties of wairua (spiritual dimension) (Wallace, 2018). To ensure rich qualitative data (Patton, 2015), cultural narrative was captured through the use of a one-to-one, semistructured interview method.

In order to identify emergent ngā aroro, the participants and the researcher needed to be culturally present and culturally sensitive in particular to the possibility of the sharing of whakapapa kōrero or oral histories, and allowances were made to accommodate free-flowing narratives (Wallace, 2018). The base questions were piloted and refined where required to ensure clarity. The four participant interview questions were:

1. What should culturally effective social work supervision include?

2. Who should have access to culturally effective social work supervision?

3. Who should provide culturally effective social work supervision?

4. What are the skills, values and principles that could inform culturally effective social work supervision?

\section{Sampling}

Purposeful sampling was used and included social workers who, at the time of the research, worked and resided in Te Taitokerau-Northland, Aotearoa. The potential participants needed to be members of the professional bodies of the Aotearoa New Zealand Association of Social Workers (ANZASW) and / or registered social workers with the Social Workers Registration Board (SWRB). A professional membership was viewed as being a necessary participant criterion due to the social worker requirements inherent in membership with a professional body, particularly in terms of demonstrating an ability to work with Māori (SWRB, 2017) and in accessing regular supervision (SWRB, 2017). Furthermore, this would ensure both that the focus remained on the social worker as opposed to the organisation (Moyle, 2014) and the participant's organisational permission was not needed.

To ensure that new social work graduates had sufficient social work supervision knowledge and experience, the selection criteria included having at least two years of social work practice experience, having attended social work supervision regularly (i.e., one hour minimum at least once a month during those two years) and having provisional professional membership with ANZASW or SWRB.

In order to tap into potential supervision participants and ensure that both supervisees and supervisors met the research participant criteria, a call for research participants was made through the ANZASW Call for Research Participants guided process. In response to this call, seven social workers expressed an interest in being research participants. Six participants were subsequently selected on the basis that they met the research selection criteria. They then completed the participant consent form to be interviewed as a social work supervisor or supervisee.

Of particular importance is that the research catered for a uniquely wāhine Māori perspective to be appreciated as four of the six participants identified as Māori, with two having mixed heritage that included Māori (Wallace, 2018). Two of the six participants identified as either Pākeha (non-Māori) or New Zealander. These two participants both acknowledged the strong connections they had to the values, beliefs and practices from Te Ao Māori, in addition to working predominately with Māori whānau.

\section{Interviews}

Two participants were employed by nongovernmental organisations and another 
two participants by statutory organisations. Additionally, two participants had their own, individual, private practices. The iwi affiliations of the participants included Te Taitokerau iwi and iwi from across Aotearoa. The practice experience of the participants was broad and included having been involved in the following aspects of social work: community development, youth justice, care and protection, residential social work, social work education, teen parenting, violence prevention, the provision of supervision, working with older people, and health.

Research interview guidelines (Patton, 2015) were followed; the interviews were recorded and took approximately an hour. The interviews followed the whakatau (a process of welcome) by opening and closing with karakia (incantations), mihimihi (acknowledgements), as well as the sharing of kai (food) at the end of the interview. The interviewer and interviewee debriefed after the interview was completed and general notes were taken as to any emerging perceptions or themes. The interview venue was flexible, thus included interviews being conducted in the participant's or researcher's home.

The interview recordings were transcribed verbatim and the interview transcripts were returned to the participants to review and request amendments if required. The research participants' Guidelines for Amendments included a timeframe of review for the participants' transcript of two weeks with a follow-up hui (meeting) with the researcher if necessary (Wallace, 2018).

\section{The Whakawhanaungatanga Research Advisory Roopu}

The use of the Whakawhanaungatanga Research Advisory Roopu was an essential feature of the methodology for the research with similar types of roopu or groups being adopted in other kaupapa Māori research, (Ruwhiu et al., 2009). The Whakawhanaungatanga Research Advisory
Roopu provided the interdisciplinary collaborative oversight for the research to be supervised from a western research knowledge base and mātauranga Māori research or Māori knowledge base. This was achieved by having an expert in Te Reo Māori me ona tikanga (Māori language and practices) from Te Taitokerau provide integral input into the entire research project, from the consultation for the initial research proposal to the correct interpretation of ngā aroro, the use of correct dialectical terms and the appropriate dissemination of the research through whānau, hapū and iwi channels. The success of the Whakawhanaungatanga Research Advisory Roopu was dependent on the mutual respect that each research supervisor demonstrated to one another their areas of expertise and the common goal they shared to support the research and the researcher.

\section{Thematic analysis}

A thematic analysis (Patton, 2015) was enlisted to draw conceptual themes from the raw data, providing a closer understanding of ngā aroro and their true meaning in supervision. The thematic analysis process involved identifying common conceptual themes in the interview transcripts, notwithstanding that this analysis method also involved taking note of emerging conceptual themes (Mooney, 2012).

Inductive and deductive approaches were used to establish conceptual themes (Patton, 2015). The inductive approach involved reviewing and manually coding emerging ngā aroro from the participants' transcript data. This was coupled with the deductive approach reviewing and coding ngā aroro established by the documentation (oral and written) of core Te Ao Māori concepts (Thematic analysis, n.d.). In addition, fundamental validation of conceptual themes was correlated with established themes from the literature review (Mooney, 2012). Direct quotes from the participants were also included to justify a conceptual theme (Abell \& Myers, as cited in Mooney, 2012). 
Admittedly, the research sample group was small; however, when a conceptual theme is known and collectively recognised across the sample group, the justification for a concept is said to have reliability (Patton, 2015).

\section{Ethical considerations}

Prior to undertaking the research, appropriate approval was needed by kaumātua and kuia from Te Taitokerau. In terms of correct cultural practice, without the approval from kaumātua and kuia, the researcher would not have been able to progress the research proposal. The consultation process with kaumātua and kuia took approximately three months during which time three hui were organised with the researcher and kaumātua and kuia to enable discussion and reflection about the implications of this research, the conclusion of which resulted in approval for the research to proceed.

In respect of the kaupapa Māori research principle, kaua e takahia te mana o te tangata (do not trample over the mana of people) (Moyle, 2014, p. 32), the research participants were identified by an abbreviated pseudonym. The dissemination of the research information was discussed with the participants and due consideration given to institutional requirements, professional responsibilities and whānau, hapū and iwi obligations. In terms of the ownership of information, and to respect the place where the research was undertaken, the findings are inherently a part of the whānau, hapū and iwi of Te Taitokerau.

The positioning of the Māori researcher is significant in kaupapa Māori research and is said to bring intrinsic biases (Bell, 2006; Cunningham, 1998; Hollis, 2006; HollisEnglish, 2012, as cited in Moyle, 2014; Smith, 1999). In addition, for the purposes of this research, the researcher acknowledged the experience and knowledge she has on the topic of cultural supervision and the consequent power differential that this entails in positioning the research participants.
The locating of the Whakawhanaungatanga Research Advisory Roopu within the research was an essential aspect of the research methodology. In order to ensure that the membership of this roopu maintained its function and purpose, the Whakawhanaungatanga Research Advisory Roopu Agreement was developed. The agreement outlined the areas of knowledge of the advisory group membership as well as each of the research advisor's roles and responsibilities in the roopu and the research. The primary function of the roopu was for the researcher to unpack, discuss, reflect and appropriately manage any perceived or actual bias.

In addition, it was important that each aspect of the research methodology was acceptable to the participants as described in the kaupapa Māori principle, "aroha ki te tangata (a respect of people)" (Moyle, 2014, p. 31). With this principle in mind, the research participants were informed of the Whakawhanaungatanga Research Advisory Roopu and the terms of the associated agreement.

The diverse cultural realties that the participants were attuned to (highlighted in italics with pseudonyms, see excerpts in Ngā aroro-The conceptual themes section), showed their capacity to step into a supervision space that had been designed first and foremost by their own unique cultural ways of knowing and being. The following pseudonyms have been used for the six participants alongside whether they participated as a supervisor or supervisee in the research;

- ICW, SW1 and SW3 participated in the research as supervisees.

- $\quad$ SUP1, SUP2 and SUP3 participated in the research as supervisors.

\section{Pūkōrero-Findings}

The research findings (Wallace, 2018) revealed that the presence of ngā aroro in 
supervision is intrinsically linked to the views and meanings of ngā aroro given by the participants. This is clear through the oral narrative linkages to the participants' own cultural knowledge base informed by their whānau, hapū and iwi knowledge and practice. Running alongside this was the participants' level of recognition of their own individual beliefs and values and, therefore, the extent to which they placed importance on incorporating ngā aroro.

Overtones of the injustices to Māori were echoed among the participants, as were the structural barriers to accessing suitable supervision for the expression of who they are as Māori. This was evident in the recurring challenge faced by the participants with regard to the varying practice expectations that come into play across organisations for working alongside Māori. However, as much as supervision was viewed by participants as being, more often than not, managerially controlled rather than social worker driven, there was validation within the findings that ngā aroro were activated in supervision (Wallace, 2018).

This type of activation was not superficial; rather, it was a deeply meaningful and authentic cultural experience in supervision. At times, the participants expressed the resetting of their feelings of hurt and pain when ngā aroro were part of their supervision, and this provided a much-needed supportive buffer for those in particular who come up against institutional racism.

An array of skills, knowledge, personal and professional traits, supervision practice models and cultural experience were highlighted in terms of a supervisor who was culturally adept in understanding the intricacies of ngā aroro (Wallace, 2018). For example, this took the form of being able to provide guidance in terms of an imbalance of wairua (spirituality), having knowledge of whānau connections and relationships of whakapapa (genealogy) and possessing the tūpuna (ancestral) knowledge and skills of hohourongo or healing. Consequently, supervisors of this calibre were often sought through word of mouth and most likely from personal and or whānau connections, rather than from an organisational list of possible supervisors.

\section{Ngā aroro-the conceptual themes}

The participants' reflections on their supervision experiences revealed six primary conceptual themes or ngā aroro that were enablers of, and contributed to, their supervision being considered culturally effective. Emerging from the participants' narratives was a shared underlying knowingness that identifying with ngā aroro in supervision meant doing their supervision differently from clinical supervision.

Furthermore, their supervision experience was correlated to their social work practice when working alongside Māori; that is, their social work practice was more effective culturally. The six core ngā aroro identified which form the conceptual themes are as follows (Wallace, 2018).

\section{Whanaungatanga-enduring relationships}

According to Hohepa (2011), there are two distinct aspects associated with the concept of whanaungatanga. Firstly, the whakapapa or genealogy that ties relationships together; and secondly, relationships may not necessarily be based on bloodlines but are still considered kin-like. Durie (1998) and Pere (1991) added that this concept includes extended whānau as well as interprofessional relationships with Māori.

This conceptual theme captured the participants' understanding of relationships that connected them to whānau, clients, peers, colleagues and supervisor, as well as at times hapū and iwi. The two conceptual touchstones that the participants attributed to the concept of whanaungatanga were whānau and whakapapa. SW3 explained how her supervisor has an in-depth understanding of who she is by knowing her (the supervisee's) own whānau saying that: he [the supervisor] 
actually meets my needs at the times that I do use him [the supervisor]. In addition, she stated the value of understanding the interrelationship of whakapapa or genealogy and whanaungatanga:

Māori staff that are dealing with Māori clients, mokopuna [grandchildren], you know that whole understanding around whakapapa and whanaungatanga is huge and if you don't really understand it, you can ... make the work a lot harder for yourself.

Likewise, SW1 and SW3 illustrated that the customary practice of whanaungatanga occurred naturally in supervision for them as their supervisor was known to their whānau and selected because of this. At the same time, these two particular whanaungatangaconstructed supervisory relationships enabled critical reflection and professional learning to occur. This was enabled through trusting that their supervisors had sufficient understanding of the supervisees' personal qualities and attributes, and likely knowing the supervisees' roles and responsibilities within their own whānau, hapū and iwi. SW3 explained this further: I know him through ... relationships within our own whānau he's always been around and I just knew he knew me... knew things about me just through things we know. SW3 also revealed that he knows about the losses and the gains within our [the supervisee's] whole whānau... and it's being able to just sort of push me a little bit further to understand myself better.

\section{Mana and tapu-cultural safety}

Pere (1991) said that tapu can be seen as a protective element and as a measure of respecting another human being, adding that tapu is intrinsically linked to mana. Mana is referred to as having prestige or influence (Mead, 2003; Pere, 1991). According to Mead (2003), mana can also be a key mediating factor in maintaining stability or balanced approaches in personal and wider relationships.

The seamless relationship between the conceptual theme of mana and tapu was reflected upon by the participants. Their narrative included the need to preserve the inherent dignity of all peoples. For instance, SW1 said of mana and tapu that it is maintaining people's dignity from a genuine place of caring, which she described as being aroha [compassion]. SW1 recollected her experience of upholding a client's mana in a practice situation she shared with her supervisor: $I$ [the supervisee] didn't want to trample on anybody's mana. I didn't want to but I felt really aroha [compassionate] for them [the supervisee's clients].

The collective consciousness about the transgression of tapu and mana provoked considerable discussion and critical reflection during the participants' own supervision sessions. Representative of this was SUP3's reflections on the significance that tapu and mana play in maintaining respectful supervision boundaries: having that belief that everybody has a tapu and mana so it's not violating [violated] even in supervision. SUP3 further stressed that it is important for the supervisor and supervisee not to takahia or trample on a supervisor's or supervisee's mana during supervision.

\section{Tika, pono, aroha-cultural integrity}

The interaction between tika, pono and aroha is a fine-tuned interconnection based on being well informed or correct, genuine in purpose and coming from a place of aroha and compassion respectively (Mead, 2003; Tate, 2012).

The belief in the conceptual triad of tika, pono, and aroha was expressed by participants in real terms of expectations of culturally effective supervision practice either as a supervisor or supervisee. SUP2 shared her meanings of this conceptual triad: I think that people that want that [tika, pono and aroha] for supervision... want to be loved and respected and treated [with] honesty. Comparatively speaking, SW1 supervisor utilised this conceptual triad in the critical reflection phase of discussing a client issue, the outcome of which, SW1 said, was healing 
for the supervisee. In addition, participants noted that tika, pono and aroha are essential in establishing trusting supervisory relationships and enabling supervisees, as SUP3 suggested, to bring important items to supervision such as safety concerns.

\section{Manaakitanga-supportive approaches}

Manaakitanga emphasises taking care of how people are looked after and cared for with a view to the fostering and nurturing of relationships (Mead, 2003).

The conceptual theme of manaakitanga encompasses ways of providing support in supervision and stimulating critical reflection. SUP1 aligned this to her perspective of servant leadership which is in contrast to advice-giving and described how she encourages supervisees to consider or wonder what else they [the supervisees] might need to know and where they need to go. There were a number of innovative cultural methods used that demonstrated the use of supportive approaches in supervision. For example, SW1 acknowledged the progressive steps of pōwhiri or welcome that required her to have a discussion about her supervision items prior to each supervision session taking place to ensure that the rituals of the supervision encounter were appropriate.

\section{Wairuatanga-spiritual spheres}

In its essence, wairua is an essential element in directing a process of engagement of the physical and non-physical spiritual spheres; in addition, wairuatanga brings together the collective knowledge and understanding of wairua (Ruwhiu \& Ruwhiu, 2005).

The need to seek effective supervisory wairua support was a major driver for the participants, with SW3 going as far as suggesting that if her wairua is affected then depending on how bad things get, it can be quite debilitating you actually can't do anything. The overriding aspects of wairua that called for prompt supervisory support were described by SW3 as being represented by the feeling that it goes home with me it's not something I can turn off. SW1 emphasised that there's got to be that spiritual aspect that wairua aspect in supervision, and added: so we [the supervisor and supervisee] have karakia [prayer] to me [the supervisee] in Māori [there] is a deeper sense, in the meaning of karakia, which involves: karakia to the atua [gods] to the whenua [the land] to the tūpuna [ancestors] to the awa [rivers]. SW1 expressed appreciation for how your wairua heals when it comes out of cultural supervision, compared to that of clinical supervision: yeah not always [the same] with clinical cause you gotta come out with tasks.

\section{Rangatiratanga-self-determining supervision}

Self-determining indicators, according to Durie (1998) and Marsden and Royal (2003), are the broad objectives of rangatiratanga, the goal of which is the realisation of one's full potential.

This final conceptual theme embraced the innovative supervision approaches informed by mātauranga Māori or Māori knowledge. ICW articulated this by recognising in her supervision a kaupapa Māori...format, and as including a necessary part of her supervision the use of karakia as well as working through Māori models of practice. SUP3 identified how a Te Tiriti or Te Tiriti o Waitangi-based supervision approach has a part to play in meeting the needs of supervisees. ICW also made links to a Treaty-based approach to supervision as she contemplated the loss of whenua or land as a part of her social work practice experience with whānau, as her reflections show here: Māori are already in grieving due to things [confiscation of lands] that have happened with whenua [land] and so even though we [social workers] see all this grievance on top it's just a layer upon layer and underneath there's a really deep layer...having somebody [supervisor] to talk to about that deep grief is something that's really helpful. Likewise, participants highlighted the importance of supervisors 
knowing and practising ngā aroro in their wholeness, having knowledge of Te Reo Māori me ona tikanga (Māori language and practices) and having the ability to break down the complexities of ngā aroro, in addition to there being an expectation that ngā aroro are naturally applied in certain types of supervision methods.

\section{Whakawhitiwhiti kōrero-Discussion}

Examining ngā aroro revealed possible conceptual supervision frameworks which future research could explore further to uncover their potential. The initial signs are that ngā aroro supervision frameworks have a sense of collective cultural approaches, particularly in terms of enhancing critical cultural reflection (Wallace, 2018). This is expanded upon below in relation to each supervision framework.

In supervision practice, a whanaungatangaconstructed supervision framework may prioritise a supervisee's and their clients' whakapapa informed by their whānau, hapū and iwi knowledge. Perhaps a supervisor's knowledge in this framework would need to include having whakapapa knowledge about the supervisee and their clients. An addition to the critical reflection phase of supervision would include the hopes, dreams and expectations of tūpuna connected to the supervisee or the supervisee's clients and passed through the generations.

In supervision practice, a manaakitangaled supervision framework could include hapū and iwi representatives conducting group supervision in terms of supporting supervisees in critically reflecting on their cases and collective notions of care and support for whānau.

In supervision practice, a wairuatangacentred framework may focus on exploring sites of healing and opportunities for enlightenment through karakia, whakatauki (proverbial sayings), moteatea (traditional chant) from a supervisee's or supervisor's cultural repositories of knowledge.
In supervision practice, a rangatiratangabased framework could concentrate on reflecting on whānau, hapū and iwi collective meanings pertaining to one's cultural identity. In doing so, this could enable the reclaiming of the cultural centre of self for the supervisee and / or for the supervisee's whānau or the clients they are working with. Unanticipated in the findings was the opportunity to consider resetting supervision functions as Figure 1 illustrates:

\section{Limitations}

The intention of this research was not to achieve a universal understanding of ngā aroro in supervision but, rather, to gain cultural insights. Furthermore, the research is not claiming to be representative of all social workers and their notions of supervision; indeed, there may or not be transferable points among and between hapū and iwi. The transferability will be left to the meaning given by supervisees and supervisors. While a comparative gender analysis may be considered necessary, it is important to note the valuable reflective time and space the research gave to a uniquely wāhine Māori perspective along with nonMāori participants who identified strongly with Māori values, beliefs and practices.

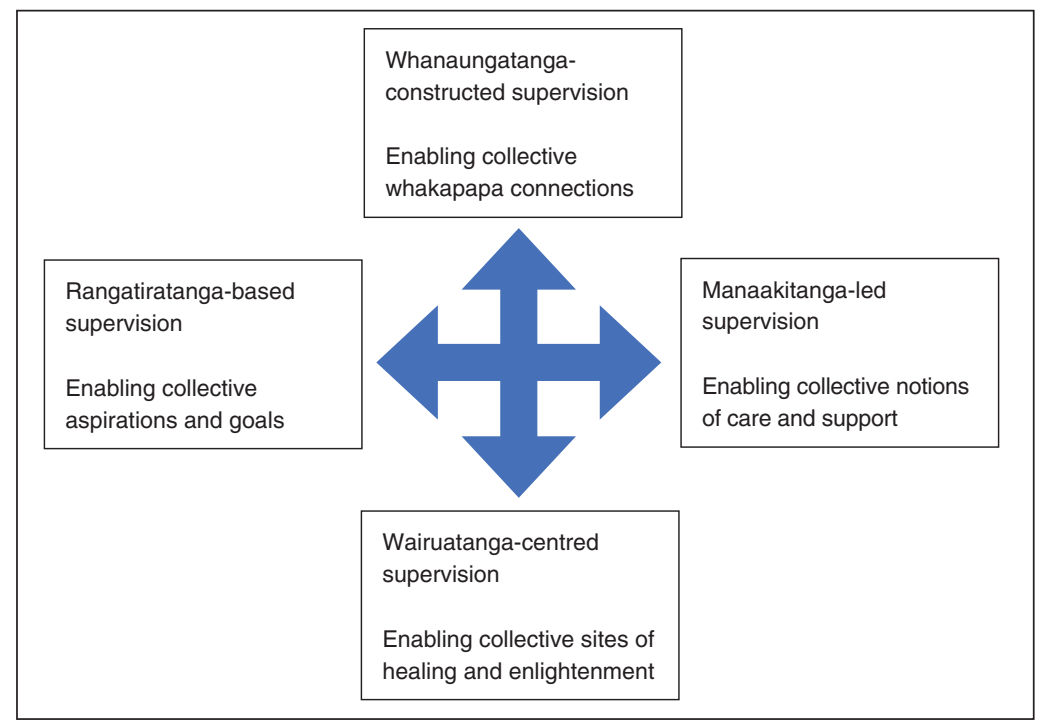

Figure 1. Ngā aroro as supervision conceptual frameworks and their functions. 


\section{Kōrero whakamutunga- Conclusions}

For social work supervisors, this research highlighted the desire of supervisees to be supported to engage with supervisors who meet their cultural needs. This poses challenges in meeting professional supervision 'norms' as, at times, this means that supervisees are seeking supervisors who may not have a social work qualification but who do have a wealth of knowledge and expertise in other fields, for example, fluency in applying cultural concepts, healing and counselling. The re-indigenising of social work supervision requires the revival of conceptual frameworks like whanaungatanga, manaakitanga, wairuatanga and rangatiratanga. This does not mean that western theories are to be rejected. It does, however, question the assumption that western perspectives can adequately define supervision theory and practice.

Implicit through the narratives of $\mathrm{He}$ Whakaputanga 1835 and Te Tiriti o Waitangi 1840 of Aotearoa, is the underscoring of ngā aroro, particularly in terms of fostering respectful relationships. This would tend to validate the proposition that engaging in culturally informed supervision should be seen as a necessity for all supervisees and supervisors in Aotearoa rather than as an option.

Creating space in social work supervision for ngà aroro is not entirely about the professional requirements of supervision. Explicit in unique cultural supervision spaces is the co-design of supervision. In this case, culturally co-designed supervision places a greater emphasis on the cultural phenomena that are occurring for the supervisee in their practice context and within the supervisee and supervisor relationship.

Indigenous supervision frameworks help to keep supervision relevant in contemporary social work settings. This signals an assurance that supervision is evolving and keeping in line with indigenous aspirations. Furthermore, it shows that the field of social work supervision is willing to be evaluated based on the cultural context within which supervision operates. Most important of all is the creation of critical reflection opportunities for social workers to enhance their own cultural capacity and to better serve the cultural needs of the whānau that social workers work alongside.

\section{References}

Barlow, C. (1991). Tikanga whakaaro. Key concepts in Māori culture (1st ed.). Auckland, New Zealand: Oxford University Press.

Bell, H. S. (2006). Exiting the matrix: Colonisation, decolonisation and social work in Aotearoa: Voices of Ngāti Raukawa ki te tonga kaimahi whānau (Unpublished masters thesis). Massey University, Palmerston North

Connolly, M., Crichton-Hill, Y., \& Ward, T. (2005). Culture and child protection: Reflexive responses. London, UK: Jessica Kingsley.

Cunningham, C. (1998). A framework for addressing Māori knowledge in research, science and technology. In Te Pumanawa Hauora (Ed.), Te Oru Rangahau: Māori Research and Development Conference (pp. 387-397). Palmerston North: Te Putahi A Toi, Massey University.

Davys, A., \& Beddoe, L. (2010). Best practice in professional supervision: A handbook for the helping professions. London, UK: Jessica Kingsley.

Davys, A., May, J., Burns, B., \& O’Connell, M. (2017). Evaluating social work supervision. Aotearoa New Zealand Social Work Review, 29(3), 108-121.

Durie, M. (1994). Whaiora: Māori health development (2nd ed.). Auckland, New Zealand: Oxford University Press.

Durie, M. (1998). Te mana, te kāwanatanga: The politics of Māori self- determination. Auckland, New Zealand: Oxford University Press.

Eketone, A. (2012). The purposes of cultural supervision. Aotearoa New Zealand Social Work Review, 24(3\&4), 20-30.

Elkington, J. (2014). A kaupapa Māori context. Aotearoa New Zealand Social Work Review, 26(1), 65-73.

Eruera, M. (2005). He kōrero korari: Supervision for Māori weaving the past into the present for the future (Unpublished master's thesis). Massey University, Palmerston North, New Zealand. Retrieved from https://mro.massey.ac.nz/handle/10179/6471

Eruera, M. (2007). He kōrero kōrari. In D. Wepa (Ed.), Clinical supervision in Aotearoa/New Zealand: $A$ health perspective. Auckland, New Zealand: Pearson Education New Zealand.

Hawkins, P., \& Shohet, R. (2012). Supervision in the helping professions (4th ed.). New York, NY: Open University Press.

Hollis, A. (2006). Pūao-te-Ata-Tū and Māori social work methods (Unpublished master's thesis). University of Otago, Dunedin, New Zealand.

Hollis-English, A. (2012). Māori social workers: Experiences within social service organisations (Unpublished doctoral thesis). University of Otago, Dunedin, New Zealand. 
Hohepa, P. (2011). Hokianga from Te Korekore to 1840 : A resource document commissioned by the Crown Forestry Rental Trust on behalf of the Hokianga whānau, hapū, land and resources claims collective. Final report. Aotearoa New Zealand.

Kadushin, A. (1976). Supervision in Social Work. New York, NY: Columbia University Press.

Marsden, M., \& Royal, T. (2003). The woven universe: Selected writings of Rev. Māori Marsden. Otaki, NZ: Estate of Rev. Māori Marsden.

Mead, H. (2003). Tikanga Māori: Living by Māori values. Wellington, Aotearoa New Zealand: Huia.

Mead, H. (2016). Tikanga Māori living by Māori values (rev. ed.). Wellington, Aotearoa New Zealand: Huia.

Mooney, H. (2012). Māori social work views and practices of rapport building with rangatahi Māori. Aotearoa New Zealand Social Work Review, 24(3\&4), 49-64.

Morrison, T. (2001). Staff supervision in social care: Making a real difference for staff and service users. Brighton, UK: Pavilion.

Moyle, P. (2014). A model for Māori research for Māori practitioners. Te Komako: Aotearoa New Zealand Social Work Review, 16(1), 29-38.

Murray, V. (2012). Hoki ki tōu maunga kia purea ai e koe ki ngā hau o Tāwhirimatea-A supervision model. Te Kamako: Aotearoa New Zealand Social Work Review, 24(3\&4), 3-11.

Patton, M. (2015). Qualitative research \& evaluation methods (4th ed.). Thousand Oaks, CA: Sage Publications.

Pere, R. (1982). Ako: Concepts and learning in the Maori tradition. Wellington, New Zealand: Te Kohanga Reo National Trust Board.

Pere, R. (1991). Te wheke a celebration of infinite wisdom Gisborne, New Zealand: Ao Ako Global Learning NZ.

Pohatu, T. (2004). Āta: Growing respectful relationships. Retrieved from http://citeseerx.ist.psu.edu/viewdoc/down load?doi=10.1.1.617.5762\&rep=re p1\&type=pdf

Rewita, T., Swann, H., Swann, B., \& Crocket, K. (2017). Where supervision and culture meet: Kawenga whakarurutanga. In K. Crocket, E. Davis, E. Kotzé, B. Swann, \& H. Swann (Eds.). Māori counselling journeys (pp. 215-227). Auckland, New Zealand: Dunmore Publishing.

Ruwhiu, L., Ashby, W., Erueti, H., Halliday, A., Horne, H., \& Paikea, P. (2009). A mana tane echo of hope: Dispelling the illusion of whānau violence-Taitokerau tāne Māori speak out. Aotearoa: Amokura Family Violence Prevention Consortium.

Ruwhiu, T. O. \& Ruwhiu, L. (2005). Ko te pae o te atua mai inga whakaaro hohonu nei, hei oranga mo te ora tangata. Te Kamako: Aotearoa New Zealand Social Work Review, 27(2), 4-19.

Scerra, N. (2012). Models of supervision: Providing effective support to aboriginal staff. Australian Aboriginal Studies 46(1), 77-85.

Shohet, R. (Ed.). (2011). Supervision as transformation: $A$ passion for learning. London, UK: Jessica Kingsley.

Smith, L. (2012). Decolonizing methodologies: Research and indigenous peoples (2nd ed.). London, UK: Zed Books.

Social Workers Registration Board. (2017). Retrieved from http://www.swrb.govt.nz/ http://swrb.govt.nz/for-social-workers/competenceassessment/

Su'a-Hawkins, A., \& Mafile'o, T. (2004). What is cultural supervision. Social Work Now, 29,10-16. Wellington: New Zealand: Department of Child Youth and Family. Retrieved from https://practice.mvcot.govt.nz/documents/ whats-new/social-work-now/news/2000-2005/swn29.pdf

Swann, H. (2017). Receiving referrals and beginning counselling. In K. Crocket, E. Davis, E. Kotzé, B. Swann, \& H. Swann (Eds.), Māori counselling journeys (pp. 121-130). Auckland, New Zealand: Dunmore Publishing.

Swann, H., Swann, B., Davis, E., Te Wiata, J., Smith, R., Crocket, K., \& Kotzé, E. (2017). Coming together apart. In K. Crocket, E. Davis, E. Kotzé, B. Swann, \& H. Swann. (Eds.), Māori counselling journeys (pp. 21-31). Auckland, New Zealand: Dunmore Publishing.

Tate, H. (2012). He puna iti i te ao mārama: A little spring in the world of light. Auckland, New Zealand: Libro International.

Thematic Analysis. (n.d.). University of Auckland. Retrieved from https://www.psych.auckland.ac.nz/en/about/ our-research/research-groups/thematic-analysis/aboutthematic-analysis.html

Thomas, C., \& Davis, S. (2005). Bicultural strengths-based supervision. In M. Nash, R. Munford, \& K. O'Donoghue (Eds.), Social work theories in action (pp. 189-204). London, UK: Jessica Kingsley Publishers.

Tsui, M. (2004). Social work supervision: Contexts and concepts. Thousand Oaks, CA: SAGE Publications.

Tsui, M., \& Ho, W. (1997). In search of a comprehensive model of social work supervision. Clinical Supervisor, 16(2), 181-205.

Wallace, E. (2018). Manawanui: Illuminating contemporary meanings of culturally effective social work supervision practice in Te Taitokerau, Northland (Unpublished master's thesis). Unitec Institute of Technology, Auckland, Aotearoa New Zealand. Retrieved from https://unitec.researchbank.ac.nz/handle/10652/4192

Webber-Dreadon, E. (1999). He taonga mo o matou Tipuna (A gift handed down by our ancestors): An indigenous approach to social work supervision. Aotearoa New Zealand Association of Social Work, Social Work Review, Te Komako, 11(4), 7-12.

Wepa, D. (2015). Cultural safety in Aotearoa New Zealand (2nd ed.). Melbourne, VIC: Cambridge University Press.

Wonnacott, J. (2011). Mastering social work supervision. London, UK: Jessica Kingsley. 